\title{
Mitochondrion-toxic drugs given to patients with mitochondrial psychoses
}

\author{
Josef Finsterer ${ }^{*}$
}

\section{Commentary}

The cause and pathophysiology of mood and psychotic disorders, including unipolar depression, bipolar disorder, and schizophrenia, is variable. Several scenarios have been proposed to explain the development of psychoses, one of which is mitochondrial dysfunction (mitochondrial mood and psychotic disorders) [1,2]. Impaired mitochondrial pathways, which may be associated with mood and psychotic disorders, include the respiratory chain (Figure 1) [1,3], the pyruvate-dehydrogenase complex, the 2-ketoglutarate dehydrogenase [4], and the polyol pathway [5]. Disturbance of the respiratory chain is the most frequent cause of mitochondrial mood and psychotic disorders. Mood and psychotic disorders in patients with mitochondrial disorders may be the sole manifestation, or one among other manifestations, of a mitochondrial disorder. Mood and psychotic disorders may be the dominant feature of the phenotype or a collateral finding, and may occur in syndromic as well as non-syndromic [5,6] mitochondrial disorders.

A recent study, published in this journal [1], aimed to assess psychiatric abnormalities in mitochondrial disorders with a proven mtDNA defect [1]. Twelve patients had a syndromic mitochondrial disorder (mitochondrial encephalomyopathy, lactic acidosis, and stroke-like episodes (MELAS), myoclonic epilepsy with ragged red fibers (MERRF), neuropathy, ataxia, and retinitis pigmentosa (NARP), progressive external ophthalmoplegia (PEO), Kearns-Sayre syndrome (KSS)) and seven patients had a non-syndromic mitochondrial disorder. The frequency of psychiatric diagnoses among these patients was reported to be $47 \%$ [1]. Psychiatric conditions may be even more common in other studies and include major depression, agoraphobia and/or panic disorder, generalized anxiety disorder, social anxiety disorder, or psychotic syndromes [7]. The medication these patients took at inclusion was provided for only nine patients. Among these drugs, however, several are reported to be mitochondriontoxic. Two patients were medicated with valproic acid, two

Correspondence: fifigs1@yahoo.de

KAR, Postfach 20, Vienna 1180, Austria with quetiapine, and one each with carbamazepine, atorvastatin, mirtazepine, metformin, and trazodone [1].

The study did not address whether, and to what degree, anti-psychotic or other medication may worsen the underlying defect due to mitochondrion-toxicity of the applied medication [1]. This is important since deterioration of the clinical presentation may not only be due to worsening of the underlying metabolic defect, but also due to mitochondriontoxicity of the applied anti-psychotic medication. Since a number of mitochondrion-toxic drugs are used to treat mood and psychotic disorders and may worsen the underlying metabolic defect, it is essential to exclude a mitochondrial metabolic defect before applying these agents. In addition to anti-psychotic drugs, patients with mitochondrial disorders and mood and psychotic disorders may also take other drugs, which may be mitochondrion-toxic. For a number of antipsychotic and other drugs, however, it is not well known whether they are truly mitochondrion-toxic, neutral or, rather, mitochondrion-protective.

Some agents described in the study have been reported to cause severe, sometimes even fatal, adverse reactions, such as valproic acid, which may cause irreversible liver failure, particularly in patients carrying POLG1 mutations [8]. Other drugs may be mitochondrion-toxic without obvious major clinical side effects, such as atorvastatin, which reduces the coenzyme- $\mathrm{Q}$ content and generally decreases mitochondrial functions [9], mirtazepine, which decreases complex-I activity [10], metformin, which inhibits complex-I of the respiratory chain [11], quetiapine, which inhibits complex-I [12], or trazodone, which collapses the mitochondrial membrane potential and imposes oxidative stress [13]. Antipsychotic medication may not only affect the function of respiratory chain complexes, but also activity of the pyruvate-dehydrogenase complex [14]. Some of the drugs applied may also have a protective effect on mitochondrial functions, such as vinpocetine [15], trimetazidine [16], sertraline [17], levetiracetam [18], bisoprolol [19], or enalapril [20].

Based on these considerations, it is advisable that patients with mitochondrial disorders receive special attention when treated with agents whose effects on mitochondria are 


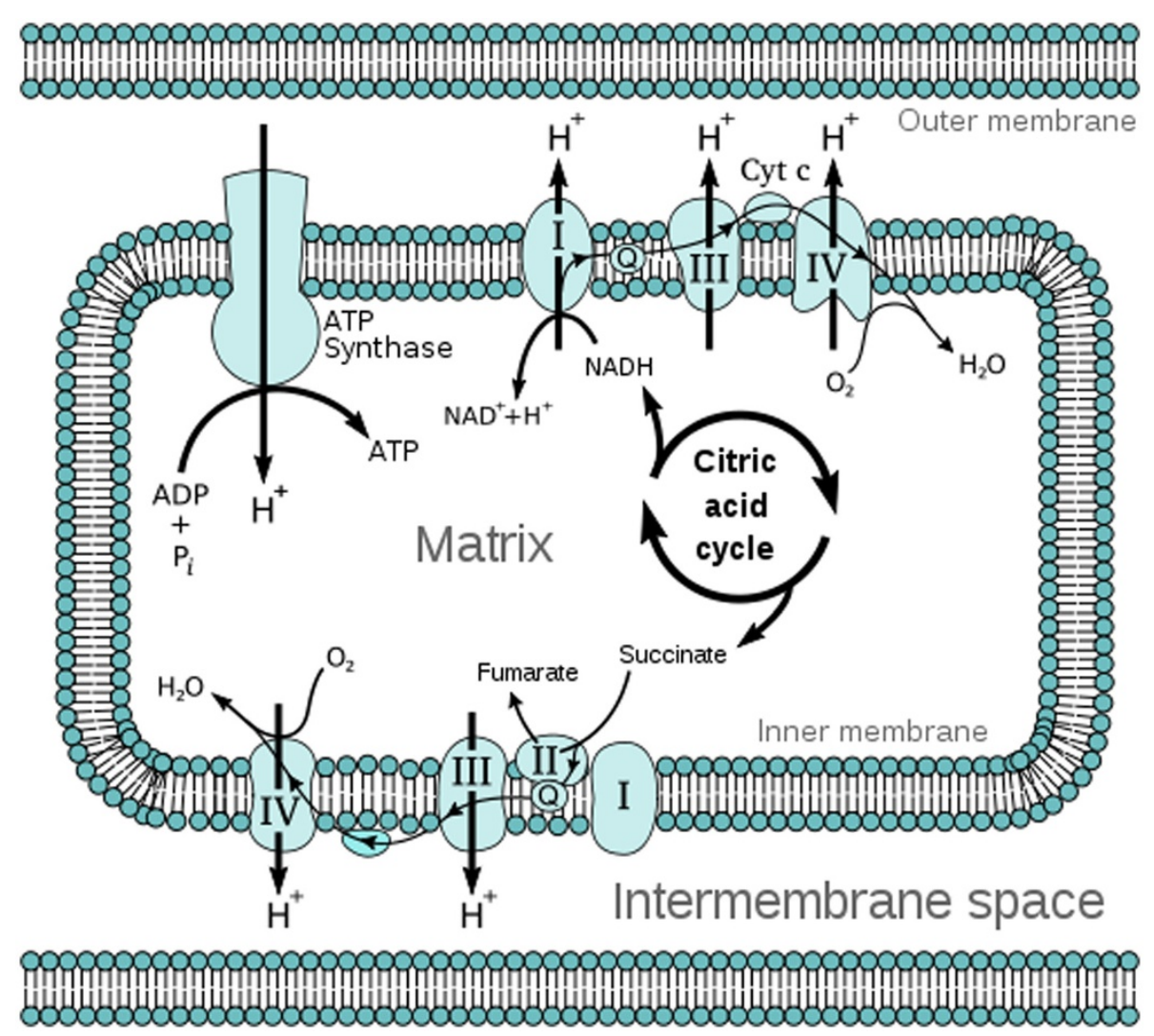

Figure 1 Eukaryotic respiratory chain located at the inner mitochondrial membrane. While electrons are transported horizontally along all respiratory complexes, protons are vertically pumped into the inter-membrane space by complexes IIII, and IV. Via complex V protons are pumped into the matrix to react with the electrons to ATP and $\mathrm{H} 2 \mathrm{O}$ (from Wikipedia).

uncertain or definitively toxic [21]. Not only may antipsychotic compounds be mitochondrion-toxic but so could be a number of other agents used in the daily routine. Since mitochondrial disorders are gaining increasing attention and thus being diagnosed more often, care has to be taken when selecting drugs for these patients. Since some patients may be highly sensitive to various compounds, these patients should be treated like patients with myasthenia gravis, who also react to contra-indicated medication with severe, occasionally fatal side-effects. Animal and human studies on the compatibility of agents with already disturbed mitochondrial metabolism, however, are required to find out which of the drugs are tolerated by patients with mitochondrial disorders and which are toxic to them.

Received: 20 March 2012 Accepted: 26 August 2012

Published: 29 August 2012

\section{References}

1. Inczedy-Farkas G, Remenyi V, Gal A, Varga Z, Balla P, Meszaros A, Bereznai B, Molnar MJ: Psychiatric symptoms of patients with primary mitochondrial DNA disorders. Behav Brain Funct 2012, 8:9.

2. Clay HB, Sillivan S, Konradi C: Mitochondrial dysfunction and pathology in bipolar disorder and schizophrenia. Int J Dev Neurosci 2011, 29:311-324.

3. Campos Y, García A, Eiris J, Fuster M, Rubio JC, Martín MA, del Hoyo P, Pintos E, Castro-Gago M, Arenas J: Mitochondrial myopathy, cardiomyopathy and psychiatric illness in a Spanish family harbouring the mtDNA 3303C > T mutation. J Inherit Metab Dis 2001, 24:685-687.

4. Guffon N, Lopez-Mediavilla C, Dumoulin R, Mousson B, Godinot C, Carrier H, Collombet JM, Divry P, Mathieu M, Guibaud P: 2-Ketoglutarate dehydrogenase deficiency, a rare cause of primary hyperlactataemia: report of a new case. J Inherit Metab Dis 1993, 16:821-830.

5. Regenold WT, Pratt M, Nekkalapu S, Shapiro PS, Kristian T, Fiskum G: Mitochondrial detachment of hexokinase 1 in mood and psychotic disorders: implications for brain energy metabolism and neurotrophic signaling. J Psychiatr Res 2012, 46:95-104.

6. Young TM, Blakely EL, Swalwell H, Carter JE, Kartsounis LD, O'Donovan DG, Turnbull DM, Taylor RW, de Silva RN: Mitochondrial transfer RNA(Phe) mutation associated with a progressive neurodegenerative disorder characterized by psychiatric disturbance, dementia, and akinesia-rigidity. Arch Neurol 2010, 67:1399-1402.

7. Mancuso M, Orsucci D, lenco EC, Pini E, Choub A, Siciliano G: Psychiatric involvement in adult patients with mitochondrial disease. Neurol SCi 2011, in press.

8. Pronicka E, Weglewska-Jurkiewicz A, Pronicki M, Sykut-Cegielska J, Kowalski P, Pajdowska M, Jankowska I, Kotulska K, Kalicinski P, Jakobkiewicz-Banecka J, Wegrzyn G: Drug-resistant epilepsia and fulminant valproate liver toxicity. Alpers-Huttenlocher syndrome in two children confirmed post mortem by identification of p.W748S mutation in POLG gene. Med SCi Monit 2011, 17:CR203-209.

9. Kucharska J, Ulicna O, Gvozdjakova A, Vancova O, Waczulikova I, Bozek P, Bada $V$ : Effects of atorvastatin on heart mitochondrial function and coenzyme $Q$ content in the experiment. Bratisl Lek Listy 2011, 112:603-604.

10. Hroudova J, Fisar Z: Activities of respiratory chain complexes and citrate synthase influenced by pharmacologically different antidepressants and mood stabilizers. Neuro Endocrinol Lett 2010, 31:336-342. 
11. Viollet B, Guigas B, Sanz Garcia N, Leclerc J, Foretz M, Andreelli F: Cellular and molecular mechanisms of metformin: an overview. Clin Sci (Lond) 2012, 122:253-270.

12. Modica-Napolitano JS, Lagace CJ, Brennan WA, Aprille JR: Differential effects of typical and atypical neuroleptics on mitochondrial function in vitro. Arch Pharm Res 2003, 26:951-959.

13. Dykens JA, Jamieson JD, Marroquin LD, Nadanaciva S, Xu JJ, Dunn MC, Smith AR, Will Y: In vitro assessment of mitochondrial dysfunction and cytotoxicity of nefazodone, trazodone, and buspirone. Toxicol Sci 2008, 103:335-345.

14. Sacks W, Esser AH, Sacks S: Inhibition of pyruvate dehydrogenase complex (PDHC) by antipsychotic drugs. Biol Psychiatry 1991, 29:176-182.

15. Tárnok K, Kiss E, Luiten PG, Nyakas C, Tihanyi K, Schlett K, Eisel UL: Effects of Vinpocetine on mitochondrial function and neuroprotection in primary cortical neurons. Neurochem Int 2008, 53:289-295.

16. Morota S, Månsson R, Hansson MJ, Kasuya K, Shimazu M, Hasegawa E, Yanagi S, Omi A, Uchino H, Elmér E: Evaluation of putative inhibitors of mitochondrial permeability transition for brain disorders--specificity vs. toxicity. Exp Neurol 2009, 218:353-362.

17. Kumar P, Kumar A: Possible role of Sertraline against 3-nitropropionic acid induced behavioral, oxidative stress and mitochondrial dysfunctions in rat brain. Prog Neuropsychopharmacol Biol Psychiatry 2009, 33:100-108.

18. Gibbs JE, Cock HR: Administration of levetiracetam after prolonged status epilepticus does not protect from mitochondrial dysfunction in a rodent model. Epilepsy Res 2007, 73:208-212.

19. Ichihara S, Yamada Y, Ichihara G, Kanazawa H, Hashimoto K, Kato Y, Matsushita A, Oikawa S, Yokota M, Iwase M: Attenuation of oxidative stress and cardiac dysfunction by bisoprolol in an animal model of dilated cardiomyopathy. Biochem Biophys Res Commun 2006, 350:105-113.

20. Boveris A, D'Amico G, Lores-Arnaiz S, Costa LE: Enalapril increases mitochondrial nitric oxide synthase activity in heart and liver. Antioxid Redox Signal 2003, 5:691-697.

21. Finsterer J: Psychosis as a manifestation of cerebral involvement in mitochondrial disorders. In Recent advances in clinical medicine. Proceedings of the International Conferences on Medical Pharmacology/Medical Histology and Embryology/Psychiatry and Psychotherapy / International Conference on Oncology. Edited by Anninos P, Rossi M, Pham TD, Falugi C, Bussing A Koukkou M. Cambridge, England, February, Recent Adv Clin Med: University of Cambridge; 2010:90-96.

doi:10.1186/1744-9081-8-45

Cite this article as: Finsterer: Mitochondrion-toxic drugs given to patients with mitochondrial psychoses. Behavioral and Brain Functions 2012 8:45.

\section{Submit your next manuscript to BioMed Central and take full advantage of:}

- Convenient online submission

- Thorough peer review

- No space constraints or color figure charges

- Immediate publication on acceptance

- Inclusion in PubMed, CAS, Scopus and Google Scholar

- Research which is freely available for redistribution 